\title{
Site-Specific Radiation Exposure during Intramedullary Nails: A Comparison between the Free-Hand Technique and the Electromagnetic Assisted Technique
}

\author{
Hiroki Kobayashi*1, Hidenori Tanikawa ${ }^{2}$, Ryo Ogawa ${ }^{3}$, Kazunari Okuma ${ }^{4}$, Shu Kobayashi ${ }^{3}$ Kengo Harato $^{3}$ \\ and Yasuo $\mathrm{Niki}^{3}$ \\ ${ }^{1}$ Department of Orthopaedic Surgery, Sanokousei General Hospital, Tochigi, Japan
}

${ }^{2}$ Department of Orthopaedic Surgery, Saiseikai Yokohamashi Tobu Hospital, Kanagawa, Japan

${ }^{3}$ Department of Orthopaedic Surgery, Keio University School of Medicine, Tokyo, Japan

${ }^{4}$ Department of Orthopaedic Surgery, Saitama City Hospital, Saitama, Japan

Received: March 12, 2018; Published: March 28, 2018

*Corresponding author: Hiroki Kobayashi, Department of Orthopaedic Surgery, Sanokousei General Hospital 1728 Horikome-chou, Sano-shi, Tochigiken, Japan,Postal code: 3278511, Tel: +81-283225222; Fax: +81-283228252, Email: supercova0205@yahoo.co.jp

Abstract

Background: We compared the operative time, fluoroscopy time and site-specific radiation exposure during intramedullary nailing for long bone fractures between classical free-hand (FH) technique and electromagnetic (EM) assisted technique.

Methods: Eleven patients with femoral or tibial fractures subjected to intramedullary nailing were studied. The intramedullary nails were performed using FH technique or EM assisted technique with the SURESHOT ${ }^{\text {TM }}$ Distal Targeting System. Ten dosimeters were attached on the patient's and surgeon's body to measure the site-specific radiation exposure. The variables, including radiation exposure (patient's eyes, patient's genitals, fracture site, surgeon's eyes, surgeon's genitals, surgeon's hands), surgical time and fluoroscopy time required for fixation of the distal locking screw, were statistically compared between group FH and group EM using two-tailed Student's t-tests.

Results: Fluoroscopy time required for fixation of the distal locking screw was significantly shorter on the Group EM $(0.57 \pm 0.40$ minutes $)$ than Group FH (2.36 \pm 1.15 minutes), while there was no significant difference in the operative time for the fixation of the distal locking screw between the two groups. Radiation exposure of the fracture site was significantly smaller in the group EM ( $2.9 \pm 1.5 \mathrm{mSv}$ ) than the group FH $(11.9 \pm 5.5 \mathrm{mSv})$. The radiation exposure of surgeon's hands was smaller in the group EM $(0.15 \pm 0.10 \mathrm{mSv})$ than the group FH $(2.00 \pm 2.56 \mathrm{mSv})$, also the radiation exposure of surgeon's eyes was smaller in the group EM $(0.065 \pm 0.069 \mathrm{mSv})$ than the group FH $(0.19 \pm 0.15 \mathrm{mSv})$, however no significant difference was observed.

Conclusion: This study suggests that the EM assisted technique is effective for reducing the radiation exposure of patients as well as the orthopaedic surgeons during Intramedullary nailing.

Keywords: Radiation Exposure; Intramedullary Nailing; Fractures; Electromagnetic Assisted Technique

Abbreviations: FT: Free-hand; EM: Electromagnetic; SD: Standard Deviation

\section{Introduction}

Intramedullary nailing has been the gold standard of treatment of long bone fractures [1,2]. In this method, the most difficult procedure is to put the distal interlocking screws accurately and quickly with minimum radiation exposure, however the positioning of the distal locking screws of an intramedullary nail is often challenging and time consuming because of potential screw malalignment and nail deformation during insertion [3,4]. The free-hand (FH) technique under fluoroscopic guidance is the gold standard for distal locking. This method relies on the expertise of both the surgeon and the X-ray technician and is largely dependent of the image intensifier, which causes radiation exposure of the patient, surgeons, and operating room staffs. Radiation exposure should be kept as low as reasonably achievable because the longterm effects of exposure to low-level radiation are still largely unknown [5].

Numerous systems, techniques, and devices have been developed over time in an attempt to overcome this problem. These include radiolucent drills and jigs [6,7], mechanical guiding 
systems attached to the proximal part of the nail $[8,9]$ or to the image intensifier [10], and computer-assisted navigation systems $[11,12]$, however none have found widespread acceptance. Recently developed aiming devices, which take nail deformation into consideration, facilitate distal interlocking with limited exposure to radiation $[13,14]$. The SURESHOT ${ }^{\mathrm{TM}}$ Distal Targeting System (Smith \& Nephew, Inc., Menphis, TN, USA) is a novel commercially available radiation-free aiming device utilizing electromagnetic (EM) field tracking technology for distal screw locking. Previous studies found that the new technique is equally effective, faster to traditional distal locking, and lessen both the radiation time and radiation exposure $[15,16]$. The aim of this study was to compare the fluoroscopy time, surgical time, and radiation exposure between the $\mathrm{FH}$ technique and the EM technique.

\section{Methods}

Study Design: From June 2013 to March 2014, nine patients with closed diaphyseal fractures of the femur of tibia were treated at our hospital. All the fractures were the result of trauma and were closed fractures classified according to the guidelines of the Arbeitsgemeinschaft für Osteosynthesefragen classification [17]. All patients were subjected to intramedullary nailing (Trigen IM
Nail systems, Smith \& Nephew, Inc., Memphis, TN, USA). Patients were divided into two groups. Four patient belonged in group $\mathrm{FH}$ who had been treated with an intramedullary nail with one or two distal locking screws inserted using the standard free-hand technique. Five patients belonged in group EM who had been treated with an intramedullary nail with one or two distal locking screws inserted using the SURESHOT ${ }^{\text {тм }}$ Distal Targeting System (Table 1). All patients received an explanation of the procedures and possible risks of the study, and gave written informed consent. This study was performed in conformity with the Declaration of Helsinki and was approved by the ethics review board at our institution.

Table 1: Demographics of the Patients. Values are Expressed as mean (Standard Deviation).

\begin{tabular}{|c|c|c|}
\hline & Group FH (n = 6) & Group EM (n = 5) \\
\hline Sex(M/F) & $2 / 4$ & $4 / 1$ \\
\hline Age(years) & $80.3(9.58)$ & $71.8(12.8)$ \\
\hline Height(m) & $1.54(0.07)$ & $1.63(0.07)$ \\
\hline Weight(kg) & $45(9.9)$ & $60(10.0)$ \\
\hline BMI & $18.7(3.4)$ & $22.6(3.6)$ \\
\hline Fracture site(femur/tibia) & $6 / 0$ & $2 / 3$ \\
\hline
\end{tabular}

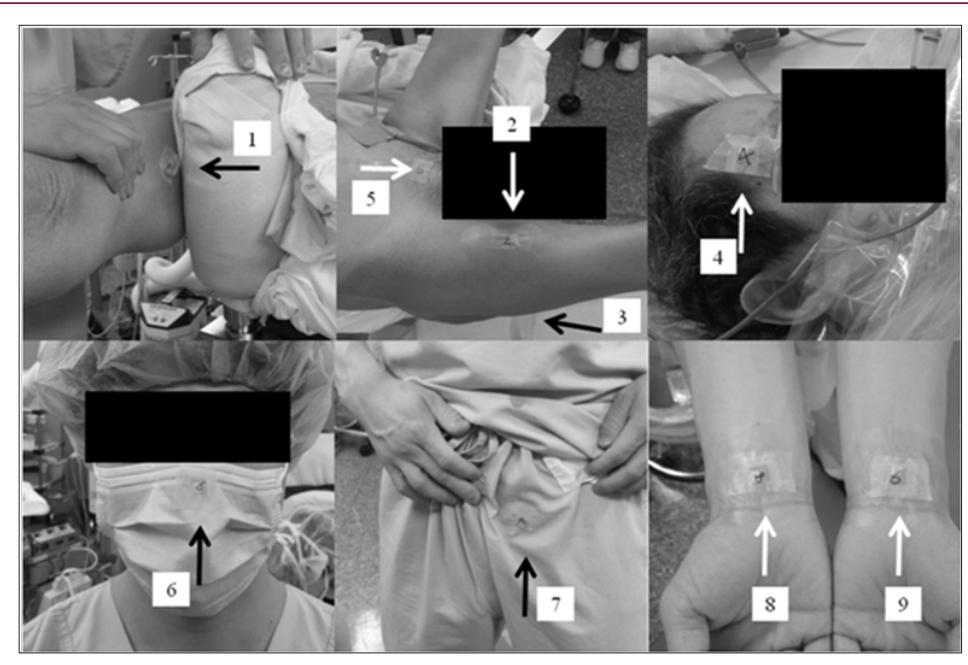

Figure 1: The Positions of the NanoDot Dosimeters: 1) Medial, 2) Anterior, and 3) Posterior side of the fracture, 4) Patient's eye, 5) Patient's pubis, 6) Surgeon's eye, 7) Surgeon's pubis, 8,9) Surgeon's hands.

Surgical Technique: Fracture reduction and implant insertion was performed with the patient under general or regional anesthesia in a standard fashion according to the guidelines given by the manufacturer. Intraoperative fluoroscopic equipment (SIEMOBIL Compact L, SIEMENS AG, Munich, Germany) was used to reduce the fractures and confirm the position of the distal locking screws during surgery. Fluoroscopic guidance was used routinely in group FH for inserting the distal locking screws and the technique is well known. Fluoroscopic guidance was used in group EM to conform positions of the distal locking screws. Luminescent nanoDot (Nagase Landauer, Ltd., Ibaraki, Japan) dosimeteres were used to radiation dose during surgeries. Ten nanoDot dosimeters were attached on the following sites of the patient's and surgeon's body: Medial site of the fracture, anterior site of the fracture, posterior site of the fracture, patient's eye, patient's pubis, surgeon's eye, surgeon's pubis inside a lead apron, surgeon's right hand, surgeon's left hand, non-radiation site as control. The nanoDot dosimeters on the fracture site were attached by surgical tapes and covered with sterilized films. The nanoDot dosimeters placed on the surgeon's hands were also covered with sterilized films. After the surgery, we collected all nanoDot dosimeters and the staffs of Nagase Landauer analyzed them. The locations of the nanoDot dosimeters were not explained to the staffs to blind this study (Figure 1).

Outcome Measures and Statistics: Surgery and fluoroscopy time to insert one screw, and radiation doses of nanoDot dosimeters were evaluated in this study for group FH and EM. Definition of the distal screw insertion time was set from the moment when surgeons used a fluoroscopy to confirm the locations of the distal holes to the moment when they finished the distal screw insertions. 
The radiation dose of the fracture site was calculated as the average of those of anterior, posterior, and medial of the fracture sites, and the radiation dose of the surgeon's hand was calculated as the average of those of the right hand and left hand. Data are presented as mean \pm standard deviation (SD). Two-tailed Student's t-tests were used to compare variables between the two groups, with an alpha level set at 0.05 .

\section{Results}

The distal screw insertion times were $8.1 \pm 2.1$ minutes in group FH and $6.2 \pm 1.5$ minutes in group EM. There was no significant difference between two groups. Fluoroscopy times of one distal screw insertion were $2.3 \pm 1.2$ minutes in group $\mathrm{FH}$ and $0.57 \pm$ 0.40 minutes in group EM. Group FH showed significantly reduced fluoroscopy time $(\mathrm{P}<0.05)$ (Table 2). The radiation exposure doses at the fracture site were $11.9 \pm 5.5 \mathrm{mSv}$ in group $\mathrm{FH}$ and $2.9 \pm 1.5$ $\mathrm{mSv}$ in group EM, showing significantly less radiation exposure dose in group FH $(\mathrm{P}<0.05)$. The radiation exposure doses of surgeon's hand in group $\mathrm{FH}(2.0 \pm 2.6 \mathrm{mSv})$ were increased than those in group EM $(0.15 \pm 0.09 \mathrm{mSv})$, and the radiation exposure doses of surgeon's eyes in group FH $(0.19 \pm 0.15 \mathrm{mSv})$ were increased than those in group EM $(0.065 \pm 0.069 \mathrm{mSv})$, however no significant difference was seen between the two groups. With regard to the other sites, there were no significant differences in the radiation exposure doses between group FH and group EM (Table 2).

Table 2: Fluoroscopy Time and Surgical Time for the Fixation of One Distal Locking Screw.

\begin{tabular}{|c|c|c|c|}
\hline & Group FH & Group EM & P \\
\hline $\begin{array}{c}\text { Operative time to } \\
\text { insert a screw (min) }\end{array}$ & $8.1(2.1)$ & $6.2(1.5)$ & 0.13 \\
\hline $\begin{array}{c}\text { Fluoroscopy time to } \\
\text { insert a screw (min) }\end{array}$ & $2.3(1.2)$ & $0.57(0.4)$ & $<0.05$ \\
\hline $\begin{array}{c}\text { Radiation exposure } \\
\text { doses (mSv) }\end{array}$ & $11.9(5.5)$ & $2.9(1.5)$ & $<0.05$ \\
\hline Fracture site * & $0.0075(0.011)$ & $0.0051(0.010)$ & 0.72 \\
\hline Patient's eye & $0.34(0.45)$ & $0.042(0.033)$ & 0.17 \\
\hline Patient's gonads & $0.19(0.15)$ & $0.065(0.069)$ & 0.12 \\
\hline Surgeon's eye & $0.011(0.016)$ & $0.031(0.058)$ & 0.43 \\
\hline Surgeon's gonads & $2.0(2.6)$ & $0.15(0.097)$ & 0.14 \\
\hline Surgeon's hand & $0.0074(0.011)$ & $\begin{array}{c}0.00019 \\
(0.00042)\end{array}$ & 0.16 \\
\hline $\begin{array}{c}\text { Control (non- } \\
\text { radiation site) }\end{array}$ & & \\
\hline
\end{tabular}

Values are Expressed as mean (Standard Deviation). *Indicates Significant Difference between the Two Groups $(p<0.05)$.

\section{Discussion}

Our study had indicated that the fixation of long bones using the intramedullary nails with EM guidance significantly decreased the radiation exposure time to the patients and surgeons and they also decreased the radiation exposure dose to both the surgeon's hands and fracture site. However no significant difference was found in the operative time to fix the distal locking screw between the FH group and EM group, both techniques are clinically effective as all screws were inserted correctly, and the EM assisted technique may be superior to the FH technique in terms of the less radiation exposure during the surgery. Some previous studies have confirmed the superiority of the EM technique in less radiation exposure time compared to the FH technique $[15,16,18,19]$. Maqungo surveyed 81 long bone fractures with intramedullary nails and concluded that the EM assisted technique significantly reduced radiation exposure during placement of distal interlocking screws without sacrificing operative time.

Chan and Burris, in their study of 40 intramedullary nails, documented that no radiation was required for placing screws using the EM assisted technique. The set-up time and operative time for distal interlocking screws were significantly reduced. With the FH technique, surgeons need to prepare the position of fluoroscopy exactly parallel to the distal holes of the intramedullary nail because accurate circle images of the distal holes are essential to make screw holes using a radiolucent drill. This setup procedure and radiation exposure during the drilling results in longer radiation exposure time of FH technique compared with the EM assisted technique, which does not need fluoroscopy to find the positions of the distal holes. Although the results of less radiation exposure time in group EM are supported by those previous studies, the operative time for distal locking screw are similar between group FH and group EM in our study.

In comparison with a previous study, although the distal screw insertion time of 511 seconds for group FH was almost the same as our study, the fluoroscopy time of group EM was 267 seconds and was almost half of the time in our study [20]. This discrepancy may be caused by the operative procedure in the present study. We routinely used the fluoroscopy for a short time in group EM to confirm that the distal locking screws passed through the distal holes of the intramedullary nail. This procedure may prolong the operative time for distal screw insertion in group EM in this study. The strength of our study is that we have measured absorbed radiation using dosimeters as well as the radiation time and operative time. To our knowledge, this is the first study which measured the site specific radiation doses during intramedullary nails. There is considerable concern about the occupational exposure of trauma surgeons to ionizing radiation [21-25].

Recent studies revealed an increased risk of cancer, mainly attributable to radiation exposure, among orthopaedic surgeons $[21,25]$. Chou conducted a cross-sectional survey of female orthopedic, urology, and plastic surgeons about cancer prevalence. They reported that female orthopaedic surgeons have a 1.85-fold increased prevalence of cancer generally and 2.9-fold increased prevalence of breast cancer compared to general female population of similar age and race [25]. Another study showed a statistically significant increased risk of cancers in the exposed orthopedic surgeon group over a 24 year period. There was an incidence of 29 $\%$ compared with $6 \%$ and $4 \%$ in the non-exposure cohorts [26]. Based on 2007 recommendations of the International Commission on Radiological Protection (ICRP), the limit for effective dose for occupational exposure is set at $20 \mathrm{mSv}$ per year, averaged over five 
years, with no more than $50 \mathrm{mSv}$ in any one year, while the annual limit for the equivalent dose to eye lens, skin and hands and feet is 150, 500 and $500 \mathrm{mSv}$, respectively.

Furthermore, a resent recommendation from the International Atomic Energy Agency suggest lowering of ocular occupational limits from $150 \mathrm{mSv}$ per year to $20 \mathrm{mSv}$ per year [27]. The radiation dose of the nanoDot at the intermediate between eyes is equal to ocular dose. From the results of this study, if a surgeon did more than 121 operations of intramedullary nailing using $\mathrm{FH}$ technique, the cumulative ocular dose would exceed the limits (20 mSv per year) proposed by the International Atomic Energy Agency. Using the EM assisted technique may reduce the risks of excessive radiation exposure of the surgeons and operative staffs during the intramedullary nails. EM assisted technique reduced the radiation exposure of surgeon's hands and eyes by $56 \%$ and $32 \%$, respectively. Another effective way to avoid radiation exposure to hands and eyes is to wear leaded gloves and eye protection. Leaded groves reduced hand exposure by $69.4 \%$, while leaded eye glasses decreased eye exposure by $65.6 \%$ [28].

Even though the risks are reduced well below occupational dose limits, radiation exposure should be kept as low s reasonably achievable because the long-term effect $s$ of low-level radiation and their relationship to different types of cancer are still largely unknown [29]. The present study has several limitations. The relatively small number of patients included in the study does not enable a firm conclusion. A follow-up study limited to tibial or femoral nails with adequate numbers may provide further evidence of the efficacy and safety of the SURESHOT ${ }^{\mathrm{TM}}$ Distal Targeting System which would reduce the use of fluoroscopic guidance.

\section{Conclusion}

In conclusion, we compared the operative time, fluoroscopy time and radiation exposure during distal screw insertion of intramedullary nails between FH technique and EM assisted technique. EM assisted technique decreased the fluoroscopy time, radiation exposure to the patients and surgeons. The EM assisted technique (SURESHOT ${ }^{\mathrm{TM}}$ Distal Targeting System) may be superior to the classical FH technique in terms of radiation exposure.

\section{Declarations}

Ethics Approval and Consent to Participate: This study followed the Declaration of Helsinki and was approved by the local ethics committee of the Saitama City Hospital, Saitama, Japan.

Availability of Data and Materials: The datasets used and/ or analyzed during the current study are available from the corresponding author on reasonable request.

Competing Interests: The authors declare that they have no competing interests.

Authors Contributions: HK and HT designed the study. HK, RO and $\mathrm{KH}$ wrote the manuscript. HK, YN, and SK evaluated the data. HT, HT and KO performed the experimental work. All authors read and approved the final manuscript.

\section{Acknowledgement}

We are grateful to Mr. Fumiaki Tatsuta and Mr. Yoshirou Takizawa for their help and support with measurement of radiation exposure. Also we would like to thank Ms. Sumi Yamashita and Ms. Shuko Kobayashi for technical assistance.

\section{References}

1. Brumback RJ, Reilly JP, Poka A, Lakatos RP, Bathon GH, et al. (1988) Intramedullary nailing of femoral shaft fractures. Part I: Decisionmaking errors with interlocking fixation. J Bone Joint Surg Am 70(10): 1441-1452.

2. Asche G (1989) Results of the treatment of femoral and tibial fractures following interlocking nailing and plate osteosynthesis. A comparative retrospective study. Zentralbl Chir 114(17): 1146-1154.

3. Krettek C, Mannss J, Könemann B, Miclau T, Schandelmaier P, et al. (1997) the deformation of small diameter solid tibial nails with unreamed intramedullary insertion. J Biomech 30(4): 391-394.

4. Noordeen HH, Sala MJ, Belham GJ (1993) Insertion of distal screws in interlocking intramedullary nails. Injury 24: 357-358.

5. Kirousis G, Delis H, Megas P, Lambiris E, Panayiotakis G (2009) Dosimetry during intramedullary nailing of the tibia. Acta Orthop 80(5): 568-572.

6. Pennig D, Brug E, Kronholz HL (1998) A new distal aiming device for locking nail fixation. Orthopedics 11(12): 1725-1727.

7. Hashemi-Nejad A, Garlick N, Goddard NJ (1994) A simple jig to ease the insertion of distal screws in intramedullary locking nails. Injury 25(6): 407-408.

8. Anastopoulos G, Ntagiopoulos PG, Chissas D, Papaeliou A, Asimakopoulos A (2008) Distal locking of tibial nails: a new device to reduce radiation exposure. Clin Orthop Relat Res 466(1): 216-220.

9. Pardiwala D, Prabhu V, Dudhniwala G, Katre R (2001) The AO distal locking aiming device: an evaluation of efficacy and learning curve. Injury 32(9): 713-718.

10. Tyropoulos S, Garnavos C (2001) A new distal targeting device for closed interlocking nailing. Injury 32(9): 732-735.

11. Malek S, Phillips R, Mohsen A, Viant W, Bielby M, Sherman K (2005) Computer assisted orthopaedic surgical system for insertion of distal locking screws in intra-medullary nails: a valid and reliable navigation system. Int J Med Robot 1(4): 34-44.

12. Suhm N, Messmer P, Zuna I, Jacob LA, Regazzoni P (2004) Fluoroscopic guidance versus surgical navigation for distal locking of intramedullary implants. A prospective, controlled clinical study. Injury 35(6): 567-574.

13. Gugala Z, Nana A, Lindsey RW (2001) Tibial intramedullary nail distal interlocking screw placement: comparison of the free-hand versus distally-based targeting device techniques. Injury 32 Suppl 4: 21-25.

14. Krettek C, Könemann B, Miclau T, Kölbli R, Machreich T, et al. (1999) a mechanical distal aiming device for distal locking in femoral nails. Clin Orthop Relat Res 364: 267-275.

15. Moreschini O, Petrucci V, Cannata R (2014) Insertion of distal locking screws of tibial intramedullary nails: a comparison between the freehand technique and the SURESHOT ${ }^{\mathrm{TM}}$ Distal Targeting System. Injury 45(2): 405-407.

16. Uruc V, Ozden R, Dogramaci Y, Kalaci A, Dikmen B, et al. (2013) The comparison of freehand fluoroscopic guidance and electromagnetic navigation for distal locking of intramedullary implants. Injury 44(6): 863-866.

17. Newey ML, Ricketts D, Roberts L (1993) The AO classification of long bone fractures: an early study of its use in clinical practice. Injury 24(5): 309-312. 
18. Maqungo S, Horn A, Bernstein B, Keel M, Roche S (2014) Distal interlocking screw placement in the femur: free-hand versus electromagnetic assisted technique (sureshot). J Orthop Trauma 28: e281-283.

19. Chan DS, Burris RB, Erdogan M, Sagi HC (2013) the insertion of intramedullary nail locking screws without fluoroscopy: a faster and safer technique. J Orthop Trauma 27(7): 363-366.

20. Hoffmann M, Schröder M, Lehmann W, Kammal M, Rueger JM, et al. (2012) next generation distal locking for intramedullary nails using an electromagnetic X-ray-radiation-free real-time navigation system. Trauma Acute Care Surg 73(1): 243-248.

21. Somerson JS, Rowley D, Kennedy C, Buttacavoli F, Agarwal A, et al. (2014) Electromagnetic navigation reduces surgical time and radiation exposure for proximal interlocking in retrograde femoral nailing. J Orthop Trauma 28(7): 417-421.

22. Chou LB, Cox CA, Tung JJ, Harris AH, Brooks-Terrell D, et al. (2010) Prevalence of cancer in female orthopaedic surgeons in the United States. J Bone Joint Surg Am 92(1): 240-244.

23. Ricci WM, Black JC, McAndrew CM, Gardner MJ (2015) What's New in Orthopaedic Trauma. J Bone Joint Surg Am 97(14): 1200-12007.
24. Canham CD, Williams RB, Schiffman S, Weinberg EP, Giordano BD (2015) Cumulative Radiation Exposure to Patients Undergoing Arthroscopic Hip Preservation Surgery and Occupational Radiation Exposure to the Surgical Team. Arthroscopy 31(7): 1261-1268.

25. Chou LB, Lerner LB, Harris AH, Brandon AJ, Girod S, et al. (2015) Cancer Prevalence among a Cross-sectional Survey of Female Orthopedic, Urology, and Plastic Surgeons in the United States. Womens Health Issues 25(5): 476-481.

26. Mastrangelo G, Fedeli U, Fadda E, Giovanazzi A, Scoizzato L, et al. (2005) Increased cancer risk among surgeons in an orthopaedic hospital. Occup Med (Lond) 55(6): 498-500.

27. International Atomic Enerty Agency (2013) Implications for occupational radiation protection of the new dose limit for the lens of the eye. Vienna, Austria.

28. Hoffler CE, Ilyas AM (2015) Fluoroscopic radiation exposure: are we protecting ourselves adequately? J Bone Joint Surg Am 97(9): 721-725.

29. Cohen BL (2002) Cancer risk from low-level radiation. AJR Am J Roentgenol 179: 1137-1143.
(C) (7) This work is licensed under Creative

Submission Link: https://biomedres.us/submit-manuscript.php

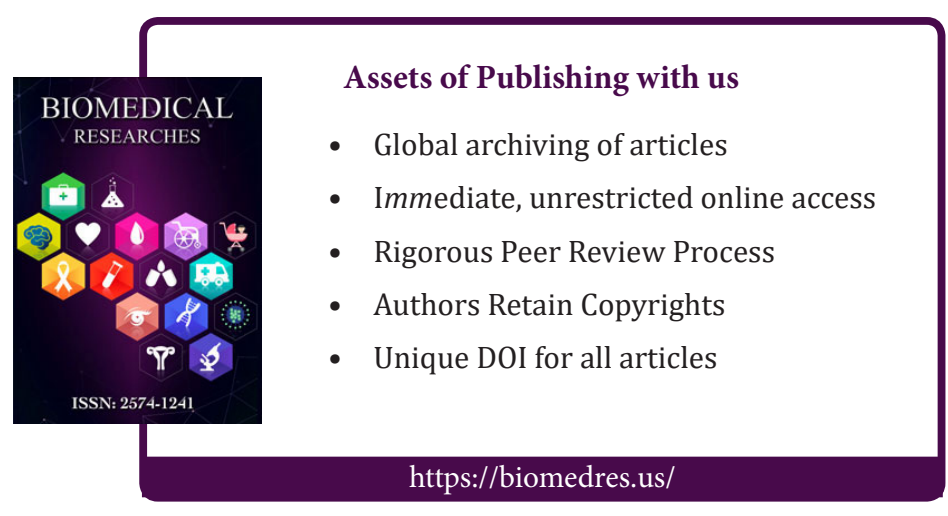

